\title{
O uso da escala geográfica na saúde pública: as escalas da leishmaniose visceral
}

\author{
The use of the geographic scale in health: the scales of visceral \\ leishmaniasis
}

Patrícia Sayuri Silvestre Matsumoto (https://orcid.org/0000-0001-7205-7557) ${ }^{1}$

Lourdes Aparecida Zampieri D'Andrea (https://orcid.org/0000-0002-3480-1426) ${ }^{2}$

${ }^{1}$ Faculdade de Ciências e Tecnologia de Presidente Prudente, Universidade Estadual Paulista Júlio de Mesquita Filho. R. Roberto Simonsen, Vila Santa Helena. 19060-080 Presidente Prudente SP Brasil. pamatsumot@gmail.com ${ }^{2}$ Centro de Laboratório Regional, Instituto Adolfo Lutz. Presidente Prudente SP Brasil.

\begin{abstract}
The geographical scale has been broadly discussed in an attempt to formulate a concept that succeeds in explaining different space-related realities. In the various sectors of health planning, geographic categories and concepts have been adopted without understanding the problems inherent to the geographical scale, which directly affects public policies implemented and, consequently, people's lives. The scope of this paper was to discuss the concept of scale based on the different scale levels and the difficulty of their implementation by means of the activities of the organs that operate in public health surveillance that deal with visceral leishmaniasis. A systematic review of the literature was conducted to show how the debate about geographical scale and health is still incipient. Geographical concepts were used, integrating municipal, state and national policies from the perspective of the geographic scale. Thus, the contention is that cooperation between health agencies and society is possible by the transposition of scales, creating an environment of solidarity and a more effective health system. The discussion does not end here, but it will make it viable to reflect on the theoretical and methodological options in research and in public health.
\end{abstract}

Key words Scales, Geographic scale, Health systems agencies, Visceral leishmaniasis, Public health surveillance
Resumo A escala geográfica tem sido amplamente discutida na tentativa de formar um conceito que dê conta de explicar as diferentes realidades do espaço. Nos diversos seguimentos de planejamento em saúde, faz-se uma adoção das categorias e conceitos geográficos sem entender os problemas inerentes à escala geográfica, o que afeta diretamente nas politicas públicas implantadas e, consequentemente, na vida das pessoas. O objetivo deste artigo foi discutir o conceito de escala a partir dos seus diferentes niveis, e debater a dificuldade de articulá-los por meio da atuação dos órgãos de vigilância em saúde pública brasileira que lidam com a leishmaniose visceral. Realizamos uma revisão de literatura para demonstrar como o debate do conceito de escala geográfica com a saúde é ainda incipiente. Utilizamos conceitos geográficos, integrando as politicas municipais, estaduais e nacional sob a ótica da escala geográfica. Dessa forma, acreditamos que seja possível uma articulação dos órgãos dos sistemas de saúde com a sociedade na transposição de escalas, num acontecer solidário, produzindo um sistema de saúde mais eficaz. A discussão não será aqui esgotada, mas permitirá uma reflexão nas opções teórico-metodológicas em pesquisas e em saúde pública.

Palavras-chave Escalas, Escala geográfica, Órgãos dos sistemas de saúde, Leishmaniose visceral, Vigilância em saúde pública 


\section{Introdução}

O conceito de escala ainda não é um assunto amplamente debatido, mas tem sido largamente utilizado no âmbito da saúde pública a partir de uma concepção material, que não traduz a realidade dos sujeitos e do ambiente em consonância com a ação. Utiliza-se o conceito de região para planejar e gerir os espaços, entretanto, a escala geográfica é ainda pouco utilizada.

A saúde pública no Brasil é composta por diferentes órgãos de vigilância em saúde que regionalizam o espaço físico e a todo momento tomam decisões em esferas nacional, estaduais e municipais. As políticas públicas nacionais regem as estaduais e as municipais. Todavia, a doença não obedece as fronteiras e recortes, ela ocorre e repercute em todas as escalas, desde a lente do microscópio, podendo ser estudada até as bandas do satélite.

Nesse sentido, o objetivo deste artigo foi realizar uma reflexão acerca da escala e como ela tem sido utilizada (e deveria ser) na área da saúde. Busca-se discutir o conceito de escala geográfica e a dificuldade de escolha de seus diferentes níveis por meio da atuação do sistema de saúde. Para isso, elaboramos uma revisão sistemática de literatura com os descritores "geographic scale and health". A revisão de literatura demonstrou que é ainda incipiente a discussão da escala geográfica na saúde em uma concepção que extrapole a noção material. Isto posto, este artigo propõe uma leitura geográfica em que a intenção foi trazer o debate teórico-metodológico dos conceitos para as políticas de planejamento. Sabemos que a discussão não será aqui esgotada, haja vista a complexidade do conceito de escala e da dificuldade de implementação das reflexões aqui propostas. Não obstante, isso nos permite repensar as opções teórico-metodológicas nas pesquisas e no sistema de saúde pública.

Este artigo foi estruturado em cinco seções. Na primeira tratamos da complexidade dos termos que compõe a escala. Na segunda fazemos a revisão de literatura e discutimos como a escala é pensada nos órgãos dos sistemas de vigilância em saúde e nas políticas públicas. Na terceira definimos o que é leishmaniose visceral (LV) e seus diferentes níveis de escala a partir da atuação dos gestores em saúde na prevenção e controle desse agravo, indo das lentes do microscópio até as bandas do satélite. Na quarta abordamos o acontecer solidário por meio da transposição de escalas na área da saúde. Por fim, a quinta seção é uma síntese dos principais delineamentos.

\section{As escalas: cartográfica e geográfica}

Tradicionalmente, o conceito de escala tem sido discutido em diversas áreas do conhecimento científico ${ }^{1-6}$, buscando-se uma reflexão conceitual. A geografia não dispõe de um conceito consolidado, apoiando-se, quase sempre, no conceito de escala cartográfica ${ }^{2}$. Isso constitui uma limitação, ao mesmo tempo em que garante as raízes do conceito geográfico.

$\mathrm{Na}$ geografia, alguns autores avançaram na discussão apontando os problemas inerentes a escala $^{2,6}$, todavia sem perder de vista a noção geométrica e material. Há que se diferenciar escala cartográfica e escala geográfica, pois ambas se confundem.

Conceitualmente, a escala cartográfica é uma fração que indica a relação entre as medidas do real e aquelas da sua representação gráfica ${ }^{2}$, ou seja, uma relação matemática entre as dimensões de um objeto qualquer do mundo real e do desenho que representa ${ }^{6}$. É um recurso de medida que estabelece uma proporção entre as coisas ${ }^{5} \mathrm{e}$ exprime a representação do espaço como forma geométrica ${ }^{3}$.

Já a escala geográfica não apresenta uma definição de consenso sobre as caracterizações a que são atribuídas ao conceito, apontando questão polêmica. A problematização do conceito se deu por a escala cartográfica ter preenchido as necessidades empíricas da escala geográfica. Contudo, nas últimas décadas, se impôs exigências teóricas e conceituais para ir além de uma medida de proporção da representação gráfica do território. Isso levou a uma discussão ampliada com a expressão da representação dos diferentes modos de percepção e de concepção do real ${ }^{1}$.

Nesse sentido, a escala é um problema epistemológico e metodológico na geografia, em que a tentativa de separar conceitualmente o que metodologicamente é integrado, é um problema de difícil solução․ Portanto, é uma questão de método, em que há uma ressignificação das categorias geográficas. No entanto, o método também pode ser uma questão de escala. Está aí desenhado uma relação dialética.

Nas escalas ocorrem problemas independentes, como níveis de análise, níveis de conceituação, níveis de intervenção e níveis de realidade ${ }^{1}$. Com efeito, dificulta-se comparar valores, índices, taxas, entre outros que expressam resultados de situações determinadas a partir de processos ocorridos em diferentes níveis de escala. Ocorre uma indefinição ao se tratá-las, devido a necessidade de representação do processo, do fenôme- 
no, da dinâmica, da força, das lógicas, da forma e da estrutura, impondo o entendimento do espaço como uma síntese.

Neil Smith ${ }^{4}$ destaca a produção da escala como um processo social. Isto posto, há uma dificuldade em se formular um conceito solidificado que a defina, levando em consideração sua complexidade e abstração, haja vista que, confunde-se os termos explicativos do que é escala geográfica dissociado da escala cartográfica.

A cartografia é um instrumento utilizado para expressar resultados adquiridos pela geografia e vai apoiar a escala geográfica, uma vez que esta exprime a representação da relação que as sociedades mantêm com esta forma geométrica ${ }^{3}, \operatorname{logo}$, a escala cartográfica e a escala geográfica são indissociáveis. A escala geográfica traz subjetividade e outras acepções além da materialidade, mas sempre terá uma representação material, que se traduz na escala cartográfica. Assim, toda escala geográfica terá implícito uma escala cartográfica, mas nem toda escala cartográfica se traduzirá em uma escala geográfica. A escala geográfica vai além, traz imbuída a noção espacial, contudo carrega outros termos, conceitos e categorias geográficas. Está relacionada e permite pensar e olhar para as categorias espaço, região, lugar, paisagem e território, para citar algumas, complementando -as e garantindo-lhes significado.

Podemos pensar a escala geográfica por meio do espaço, sendo esta a categoria mais geral e que inclui as outras, revelando-se tão completa, quanto vaga. Nas pesquisas são trabalhadas uma ou outra categoria, às vezes, mais que uma. Entretanto, estas expressam um fenômeno em uma escala, ou em escalas que se superpõem. Qualquer pesquisa terá sempre uma escala de análise, trazendo tanto uma noção cartográfica como as dimensões da escala geográfica. Por tudo isso, a escala é um conceito tão complexo. Ao ir além da noção geométrica, não dá conta de explicar, em unicidade, os diferentes fenômenos - ou o mesmo fenômeno sobreposto em diferentes escalas -, sem perder o sentido. Deste modo, a escala não pode ser entendida como parte de um recorte espacial e descritivo, ou apenas do ponto de vista do conceito de região. Ela deve ser pensada conforme a pesquisa e o tema selecionado.

Ao pensar em um objeto de estudo temos, obrigatoriamente, o pensamento nas escalas. $\mathrm{O}$ que nos levaria a reflexão: existe uma escala ideal? Fazemos a escolha de uma escala e temos os fenômenos ou, contraditoriamente, a partir dos fenômenos definimos a escala? O pesquisador interage em diferentes escalas conforme objetivos e necessida- des. A partir disso, estaria fazendo uma adoção das escalas geográficas, ou seja, desenvolvendo o exercício de pensar o fenômeno em diferentes escalas, ou como nos lembra $\mathrm{Smith}^{4}$, saltando escalas.

Conforme define Souza ${ }^{6}$, a escala geográfica tem a ver com a "extensão ou magnitude do espaço que está se levando em conta”. Para este autor, a escala geográfica seria então subdividida em escala do fenômeno, escala da análise e escala da ação. A primeira estaria restrita à sua abrangência física no mundo. A segunda seria construída com base na primeira, já que a escala da análise é intelectualmente construída como um nível analítico, levantando a apreensão de características relevantes do que se investiga. E a terceira seria um aspecto específico e político, um raciocínio estratégico concernente às ações e ao papel dos agentes/sujeitos ${ }^{6}$.

Não há um consenso sobre as caracterizações a que são atribuídas ao conceito de escala geográfica. Separamos os fenômenos por nós estudados espacialmente, dividindo-os através da realidade que representam, se fundindo entre o espacial cartograficamente delimitado e a dimensão tal qual do fenômeno. Criamos, assim, o que poderíamos definir como recortes, entendidos como escalas do corpo, local, regional, nacional, global, entre todas as mais que podem ser criadas (Figura 1).

A primeira dimensão escalar seria a escala do corpo, que representa "o primeiro sítio físico da identidade pessoal, a escala do corpo, é socialmente construído"4. Esta dimensão escalar, ou mesmo da casa, é o locus da gestação da identidade, da emanação da intimidade ${ }^{4}$. Dialoga com as demais escalas, uma vez que é a visão do sujeito para o exterior, podendo ser expresso desde atravessar uma rua, até uma viagem espacial. Nesta escala, o sujeito é sensível às condições a que são impostas. É uma forma de olhar o mundo.

A escala local é a que permite uma vivência pessoal intensa do espaço. É um espaço mais ou menos restrito que vai da nossa rua à nossa cidade (ou vila, ou aldeia) à metrópole. É onde também se vinculam os níveis mais básicos da administração estatal, representando uma situação de maior proximidade física entre os cidadãos e a sede do poder estatal ${ }^{6}$. É o lugar, ou a soma deles, onde o sujeito estabelece suas relações sociais e onde as decisões acontecem e as coisas são visíveis. É na escala local que encontramos os executores das políticas públicas, onde as ações são desenvolvidas, ou não.

A regional seria um lugar não tão intenso quanto a escala local, mas uma região de um es- 


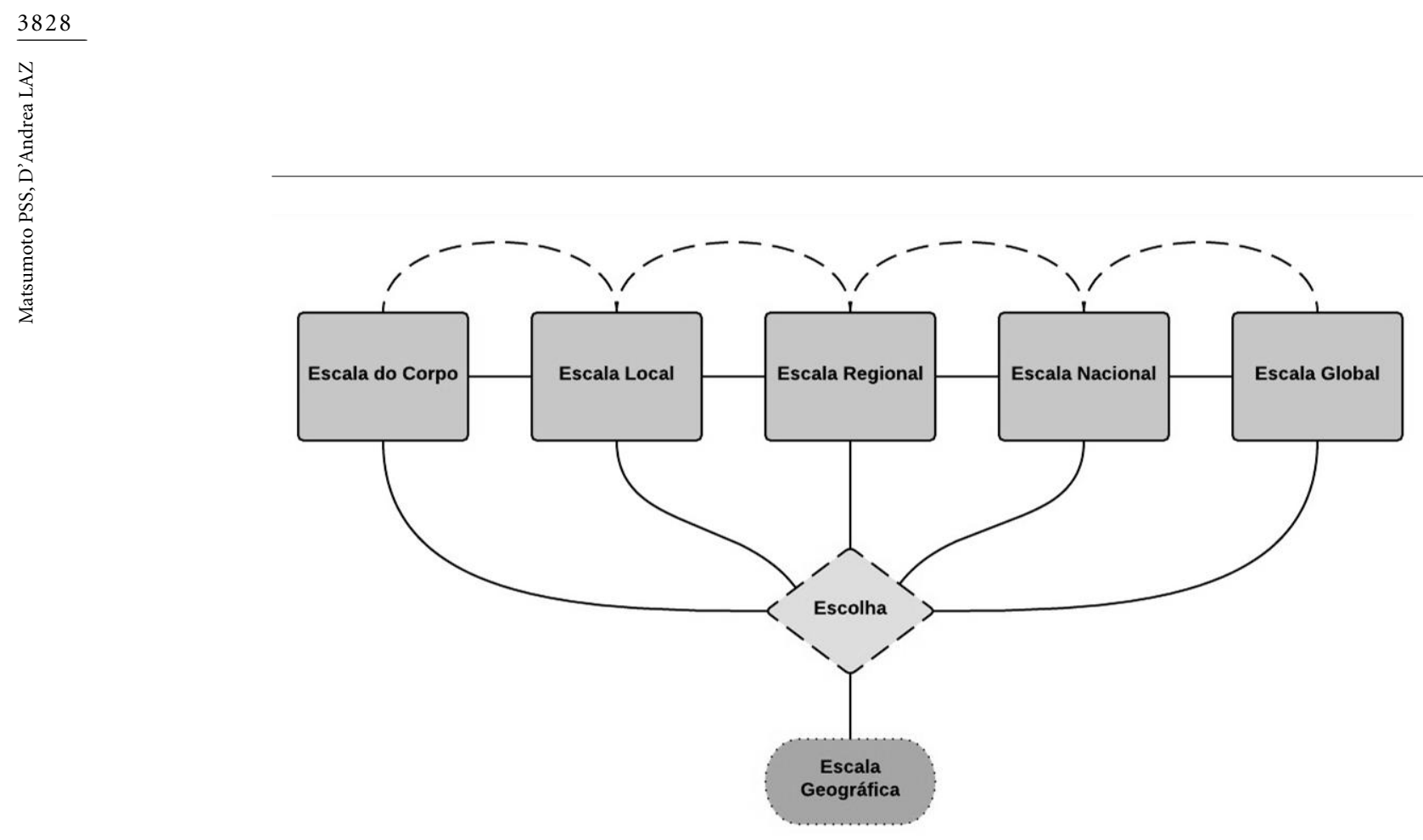

Figura 1. Diferentes níveis de escala que compõem a escala geográfica.

paço vivido e sentido/percebido, prenhe de densidade cultural-simbólica, imagética e histórica, situado entre o nível local e a escala do país, sendo esta última aquela do território ocupado por um Estado formalmente soberano ${ }^{6}$. Relaciona-se com a escala internacional e a escala de países, que em cenário geopolítico, toma decisões e cria blocos econômicos.

A global é a escala que abrange o mundo inteiro; diz respeito a fenômenos de ordem econômica no âmbito do sistema mundial capitalista ${ }^{6}$. É nesta escala que ocorre a construção para a circulação do capital e o capitalismo define a escala geográfica global precisamente à sua própria imagem ${ }^{4}$.

Com estas separações de escalas (Figura 1) para fins de melhor entendimento entre os estudos, questiona-se: é possivel pensar a escala para além destas divisões que criamos? As escalas pressupõem repensar diferentes lógicas em sua movimentação. Sua diferenciação assume, por meio das interações sociais, um sentido não somente material, trabalhada e re-trabalhada como paisagem, mas também sentido de resolução ou abstração que é empregado para entender as relações sociais ${ }^{4}$.

Diante da diversidade de escalas existentes, estamos condenados a fazer escolhas, pois a escala é mediadora dos conflitos observados ${ }^{3}$, o que levaria a nos perder pelo conceito de escala geográfica proposto, uma vez que um fenômeno se expressa ora em uma escala, ora em outra, e temos dificuldades com estas circunstâncias.

Assim, o fenômeno se apresenta de modo diferente conforme a mudança da escala. De tal modo, a escala é mediadora de pertinência já que seleciona unidade de observação e atributo; e afeta os valores analisados, necessitando de filtro e seleção ${ }^{3}$.

Há uma necessidade de as políticas de planejamento perceberem as diferenças quando modificam as escalas, sejam elas nacional, regional ou mesmo dentro de uma cidade. Há diferenças internas de um estado para o outro, indo além, entre bairros vizinhos em uma mesma cidade. $\mathrm{O}$ problema ocorre porque o planejamento em escala local deve ser ajustado e elaborado conforme as características locais, por exemplo, para uma cidade, onde diferentes grupos sociais e realidades coexistem. Por isso, a política de planejamento é uma questão de escala dentro dos princípios a que devem ser pensadas.

\section{A escala na saúde}

As ciências sociais em saúde têm introduzido reflexões teóricas em seus estudos ${ }^{7-11}$. Não obstante, há um abismo entre a teoria e a prática e o conceito de escala geográfica ainda é pouco debatido. 
Fizemos uma revisão sistemática da literatura para verificar como o conceito de escala geográfica tem sido utilizado na área da saúde. Utilizamos as bases de dados on-line Lilacs (Literatura Latino - Americana e do Caribe em Ciências da Saúde) e Medline (Literatura Internacional em Ciências da Saúde), considerando as seguintes palavras-chave como descritores (inglês): geographic scale and health; no período de 2005 a 2016. Estabelecemos como critérios revistas relacionadas à saúde, nos campos de saúde pública e ciências sociais.

Foram encontrados 422 artigos. Destes, selecionamos 382, dos quais 369 (Grupo A) fazem uso do conceito de escala na saúde indiretamente e apenas 14 (Grupo B) utilizam-no pela ótica da discussão proposta por este artigo. A revisão de literatura pode ser observada na Figura 2.

No Grupo A, há 369 artigos na condição de utilizar o conceito de escala, contudo sem realizar uma reflexão conceitual dos termos. Suas interpretações são focadas no fenômeno analisado em um determinado espaço, desconsiderando a mudança de escalas. São a maioria na literatura e consideram apenas a escala cartográfica, ou seja, sua dimensão material em relação com o mundo real. Por isso, nossa atenção é centrada no Grupo $\mathrm{B}$, que utiliza o conceito de escala geográfica, em maior ou menor profundidade, considerando as implicações da mudança das escalas na saúde.

Separamos o Grupo B em dois subgrupos: i) o uso do conceito de escala geográfica na saúde e ii) o uso e reflexão do conceito de escala geográfica na saúde. O primeiro subgrupo é aquele que traz o conceito de escala geográfica para discussão e, apesar de considerar as escalas materialmente como no grupo A, vai além ao tentar questionar problemas de representação geográfica, como a mudança de uma escala ou a agregação dos dados ${ }^{12-14}$ e o Problema da Unidade de Área Modificável $(M A U P)^{15}$. Este subgrupo analisa como um único fenômeno pode ser enxergado de diferentes formas ${ }^{16}$. Para isso, utilizam-se de ferramentas de geoprocessamento e Sistemas de Informação Geográfica; apontam a necessidade de se (re)pensar o espaço para planejá-lo melhor. Não obstante, utilizam as formas engessadas das escalas, ou seja, saltam as escalas de recorte em recorte, modificando a representação espacial, mas ainda entendendo-as como algo rígido e inflexível, em sua acepção material, ou seja, na dimensão espacial que a escala cartográfica representa.

Em contraposição, o grupo ii) conseguiu avançar nessas limitações, uma vez que estes trabalhos vislumbram a escala geográfica e a necessidade de esta ser pensada para além da mate- rialidade dos dados agregados em áreas distintas. O estudo proposto por Reardon et al. ${ }^{17}$ pensa em uma micro e macro escala difundida e o estudo de Guimarães ${ }^{11}$ propõe pensarmos as regiões de saúde pela ótica da escala geográfica. O grupo ii) é onde focamos a ideia deste artigo. Não queremos entender as escalas geográficas como escalas cartográficas, implícito o conceito de região.

Na prática, a região é um dos conceitos mais expressivos na área da saúde. Consideram-na como base física e espaço material, muitas vezes ignorando os processos sobrejacentes, ou não conferindo-lhes devido valor. Não a concebem em sua essência, como espaço não existente. As regiões de saúde são engessadas, baseadas em limitações que não respeitam a abrangência e as escalas do fenômeno ${ }^{18}$. Desde que o Sistema Único de Saúde (SUS) estabeleceu a Norma Operacional de Assistência à Saúde (NOAS) (Portaria MS/ GM n. 373 $)^{19}$ em 2002, ampliou as responsabilidades dos municípios na Atenção Básica a partir do processo de regionalização como estratégia de hierarquização dos serviços de saúde, buscando maior equidade, fortalecimento da capacidade de gestão do SUS e atualização dos critérios de habilitação de estados e municípios.

A NOAS entende a região como a base territorial de planejamento de atenção à saúde, em que há inerente, uma concepção material, um recorte cartográfico estabelecido conforme os critérios previamente selecionados.

Embora o exercício de regionalizar o espaço brasileiro seja uma tentativa de descentralizar os serviços de saúde, limita-se a traçar recortes que nem sempre condizem com a realidade dos lugares, das pessoas e dos fenômenos. As políticas territoriais do Brasil pautaram-se nas divisões regionais segundo o Instituto Brasileiro de Geografia e Estatística (IBGE), com uma concepção hierárquica e geométrica de região. Em consequência a tradição ibegeana ${ }^{11}$ das políticas territoriais, a região de saúde é considerada pelo SUS como:

espaço geográfico contínuo constituído por agrupamentos de Municípios limitrofes, delimitado a partir de identidades culturais, econômicas e sociais e de redes de comunicação e infraestrutura de transportes compartilhados, com a finalidade de integrar a organização, o planejamento e a execução de ações e serviços de saúde ${ }^{18}$.

Acontece que, as regiões de saúde são a junção de regiões previamente delimitadas de acordo com a regionalização do IBGE e não uma regionalização criada pela própria área da saúde. Esta proposta de regionalização a partir de municípios provoca distorções, 


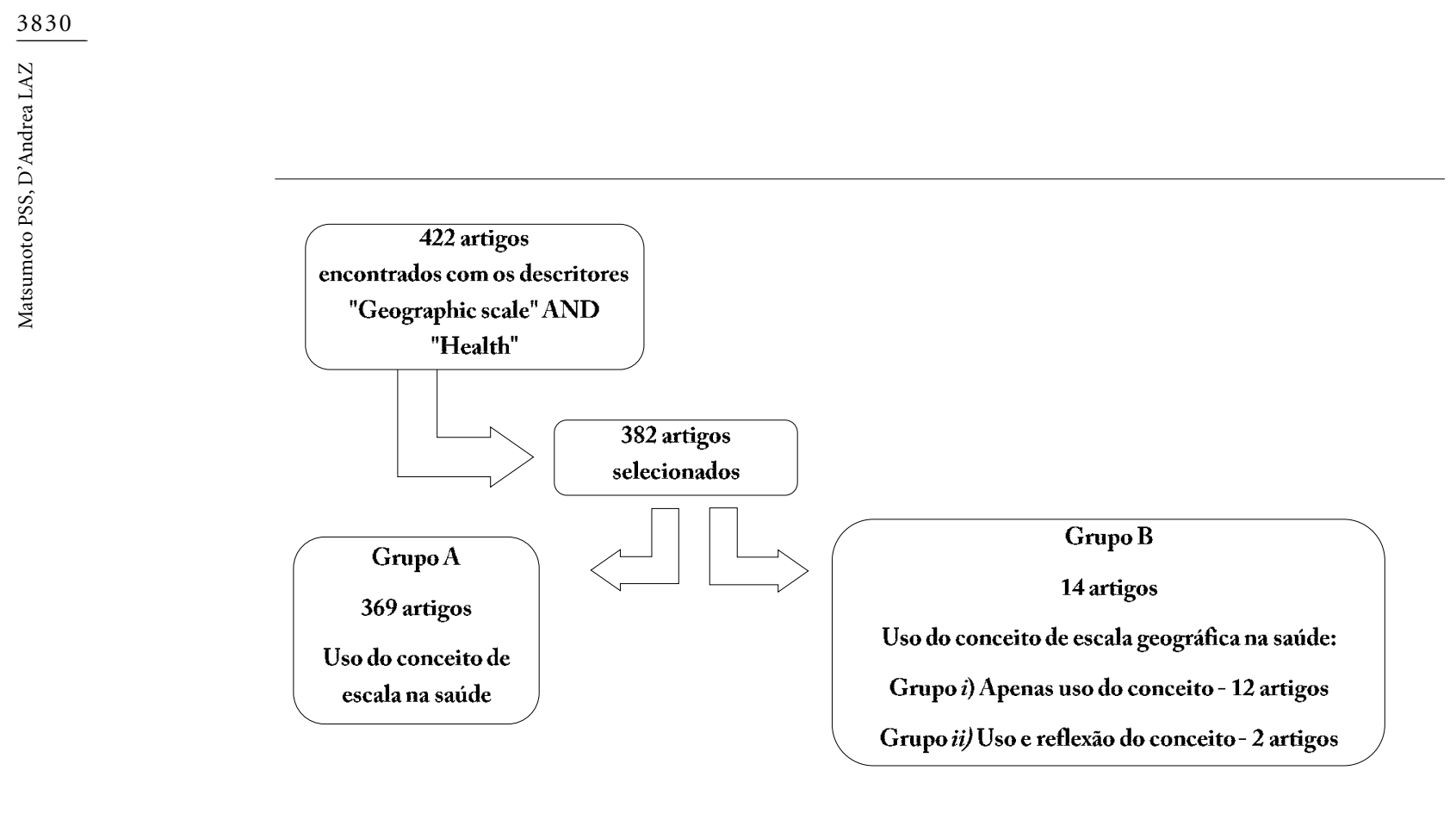

Figura 2. Revisão de literatura.

A principal delas resulta da necessidade de moldar as regiões aos limites jurídico-administrativos dos estados e municípios da federação. Do ponto de vista estatístico, isso significa, não raras vezes, recortar um certo fenômeno cuja delimitação não respeita essas fronteiras. Acaba-se por subdividir elementos que fazem parte de um mesmo processo ${ }^{11}$.

A partir destas distorções, questiona-se se é possível regionalizar a partir de identidades culturais, econômicas e sociais, e de redes, considerando um mesmo município ou os limites entre diferentes municípios. Um município por si só é desigual. De princípio, há uma diferença interna entre o que é urbano e rural. Outrossim, é composto por classes sociais distintas, realidades e pessoas diferentes em cada bairro, ou mesmo em uma rua. Há também o processo de formação histórico de cada município, suas influências culturais e intervenções políticas, entre outros. O modelo de urbanização do município, como a presença dos vazios demográficos, são fatores que influenciam diretamente a ocorrência de certos fenômenos, por exemplo, a ocorrência de doenças, destacando-se a LV.

O fato de agrupar as regiões aos limites jurídico-administrativos dos estados e municípios da federação esfacela a ideia de obedecer a abrangência do fenômeno, uma vez que esses podem ser tão diversos quanto possível. Tendo em vista essa diversidade, como considerar o agrupamento destes para se planejar a saúde de maneira eficaz?

$\mathrm{O}$ conceito de região adotado não tem sido efetivo para a resolução dos problemas de saúde. Portanto, a política de saúde pública precisa desenvolver sua própria regionalização, que não seja baseada em hierarquia e geometria, conforme as regiões do IBGE construídas no passado. Uma doença apresenta um padrão espacial diferente da outra, por exemplo, a dengue e a LV.

Uma vez estabelecidas e delimitadas as regiões de saúde, devem ser construídas com base em diálogos e necessidades, geridas por constantes discussões nas Comissões Intergestores Regionais (CIRs) a partir dos fenômenos que ali ocorrem, onde devem ser pactuados e/ou repactuados às prestações de serviços de forma a atender um determinado espaço (delimitado por área e grupos de pessoas), considerando o espaço geográfico, os equipamentos ali disponíveis e a capacidade de atendimento de cada um. A região não pode ser considerada por si só, ela precisa estar apoiada na questão escalar, especialmente na escala geográfica.

As regiões de saúde, como instrumentos, apareceriam imbuídas da escala geográfica, trazendo, a priori, as ações das políticas públicas, seja em esfera nacional, estadual ou municipal, e esta estaria em diálogo com a representação das necessidades do povo, num acontecer solidário ${ }^{11}$. As 
decisões deveriam ser pautadas em demandas da heterogeneidade das cidades (que são complexas e distintas) para então planejar, mantendo uma conversação entre os distintos níveis que ajudam a garantir a saúde da comunidade.

Assim, propõe-se o exercício de pensar em como o ciclo da LV ocorre a nível local (município), mas também como esta escala é rebatida em diversas outras que tratam a problemática estadual, união e mundial; o exercício nos fará refletir sobre a transposição de escalas no serviço de vigilância em saúde pública.

\section{Do microscópio ao satélite: os componentes da leishmanose visceral}

A leishmaniose visceral (LV) é uma doença grave, que se não diagnosticada e tratada corretamente, pode evoluir a óbito. É causada por protozoários que são transmitidos por insetos vetores, flebotomíneos, afetando homens e animais ${ }^{20-22}$, especialmente cães em área urbana ${ }^{20}$.

A LV é endêmica em 38 países no mundo ${ }^{21}$. Em 2012 foram registrados 39.653 casos, dentre os quais Índia, Bangladesh, Brasil, Etiópia, Sudão do Sul e Sudão foram responsáveis por $90 \%$ dos casos, ocupando o Brasil o oitavo lugar em frequência do número de $\operatorname{casos}^{23}$.

A doença é considerada negligenciada pela Organização Mundial da Saúde (OMS), estando entre as seis endemias prioritárias do mundo ${ }^{21,22}$. De tal modo, sua repercussão denota importância em cenário mundial, pois coloca em risco a vida de cidadãos a nível mundial, pois os vetores, hospedeiros e agentes causais não respeitam os limites de fronteiras. Através desta doença, espera-se exemplificar o que pretendemos com o uso da escala geográfica e a transposição de escalas.

Diferentes órgãos coexistem em diversas esferas de atuação e níveis de política de planejamento: união, estaduais e municipais, visando a vigilância e o controle da LV em diferentes escalas envolvidas em seu ciclo: agente causal, vetores e hospedeiros (caninos e humanos). Essas esferas de atuação são expressas pelos níveis de escalar, entendidos como local, regional e nacional, tangenciando o global ou, na escala do fenômeno, do vetor, do agente causal ou dos hospedeiros.

A nível mundial, a OMS atua através da Organização Panamericana de Saúde (OPAS). Sua atuação não é direta; seu papel se restringe a organização de eventos, como congressos e conferências, cursos, publicação de dados e relatórios, entre outros ${ }^{24}$, traçando panoramas e metas e, por isso, destacamos que a escala mundial faria parte de um contato tangencial, porém, influenciando as decisões em outros níveis. A nível regional e local, as decisões nacionais, estaduais e sobretudo municipais, são as responsáveis pela vigilância e controle da LV, de forma direta.

$\mathrm{Na}$ escala nacional, o Ministério da Saúde (MS) é o órgão que estabelece as diretrizes do programa de vigilância e controle da LV, com manuais, portarias e recomendações; investe em pesquisas em diagnóstico, tratamento e na política de assistência à saúde do Sistema Único de Saúde (SUS). Fornece os insumos para os exames diagnósticos que serão realizados tanto no cão como no humano - em escala estadual, por meio dos laboratórios centrais de referência nacional (LACENs), e municipal, por meio das secretarias municipais de saúde. É na esfera do SUS que são tomadas as decisões a nível nacional e estabelecidas as diretrizes do programa da doença com todas as normativas e ações que deverão ser executadas a partir de um padrão do que é o ideal para todos os estados. Assim, suas decisões são amplamente rebatidas em outras escalas.

Não obstante, sabendo das diferenciações existentes entre os estados brasileiros, estes têm certa autonomia para lidar com as políticas de vigilância e controle da LV. Na escala estadual, no estado de São Paulo, há órgãos específicos que lidam com os vetores e com o agente causal, são a Superintendência do Controle de Endemias (SUCEN ) do Estado de São Paulo e o Instituto Adolfo Lutz (IAL), respectivamente. O IAL é responsável pelo diagnóstico e identificação do agente causal, ou seja, os protozoários do gênero Leishmania, e a SUCEN pelo encontro e identificação dos insetos vetores, flebotomíneos. Ambos os órgãos trabalham em uma pespectiva de estudar o fenômeno através das lentes do microscópio ou até mesmo de micropartículas como o material genético, até onde a visão alcança.

Neste processo saúde-doença temos na escala local a atuação dos municípios, onde devem ser tomadas as principais decisões e desencadeadas as ações; é onde efetivamente os casos da doença acontecem. Consequentemente, o comportamento da LV num dado município pode ser entendido como fruto das decisões e das ações realizadas, contribuindo para um bloqueio da transmissão de uma determinada doença ou para sua dispersão.

No município, temos diferentes escalas de atuação da vigilância em saúde, conforme a natureza do órgão municipal: o controle de vetores/ zoonoses; o controle e vigilância dos cães; a vigilância epidemiológica no diagnóstico, tratamentos e notificação dos casos humanos; e a vigilân- 
cia sanitária na parte ambiental. Nos municípios em transmissão, quando os casos caninos de LV são confirmados, os mesmos devem ser eutanasiados por constituírem o principal reservatório da doença ${ }^{20}$. Em 2016, o Ministério da Agricultura Pecuária e Abastecimento (MAPA) autorizou o tratamento de cães com LV com o uso do medicamento Milteforan, conforme Nota técnica $\mathrm{n}^{\circ} .11 / 2016 / \mathrm{CPV} / \mathrm{DFIP} / \mathrm{DAS} / \mathrm{GM} / \mathrm{MAPA}^{25}$. Os casos humanos quando diagnosticados são tra$\operatorname{tados}^{20}$, direcionados para unidades referenciadas do SUS e pactuadas regionalmente.

$\mathrm{Na}$ escala do fenômeno, poderíamos enxergar as bandas do satélite, vislumbrando o todo, a generalização, o contexto ambiental pelos municípios, regionalmente até mundialmente; ao mesmo tempo, passear pela escala do vetor e ao dar zoom nos locais dos casos caninos e humanos, aumentando o nível de detalhe, poderemos analisar os pormenores que influenciam as condições ambientais propícias ao aparecimento da doença. Na Figura 3 foi elaborado um esquema representativo da atuação relacional entre os diferentes órgãos dos sistemas de saúde responsáveis pela vigilância do fenômeno da $\mathrm{LV}$ no estado de São Paulo.

O nó crítico que se coloca é que, apesar de todos estes orgãos atuarem para a vigilância e controle da LV, as ações não são totalmente integradas (Figura 3). Na prática, o diálogo somente ocorre com o órgão mais próximo ou aquele envolvido diretamente no fenômeno. Não há uma interação entre eles nas diferentes escalas. Propomos que a atuação da vigilânia em saúde seja realizada de forma mais integrada, por exemplo, com a criação de salas de situação a nível regional. A nível local, o grande complicador da realização das atividades de vigilância e controle da LV, bem como da eficácia no controle, é o apoderamento das informações por parte dos atores envolvidos, tanto das normativas da doença como do conhecimento da ocorrência do fenômeno em seu território de atuação. A sala de situação regional seria uma forma de propiciar esta maior integração entre os diferentes órgãos envolvidos.

Poderíamos acrescentar a esta dicussão elementos fundamentais: a sociedade civil e a questão ambiental, uma vez que a doença ocorre no ambiente (físico, antrópico, político e socioeconomicamente construído) e seus vetores, parasitos ou hospedeiros não respeitam as fronteiras de municípios, regiões de saúde, estados e até mesmo países. A sociedade civil aparece como outro componente dissociado dos demais, todos eles permeados no ambiente (Figura 4).

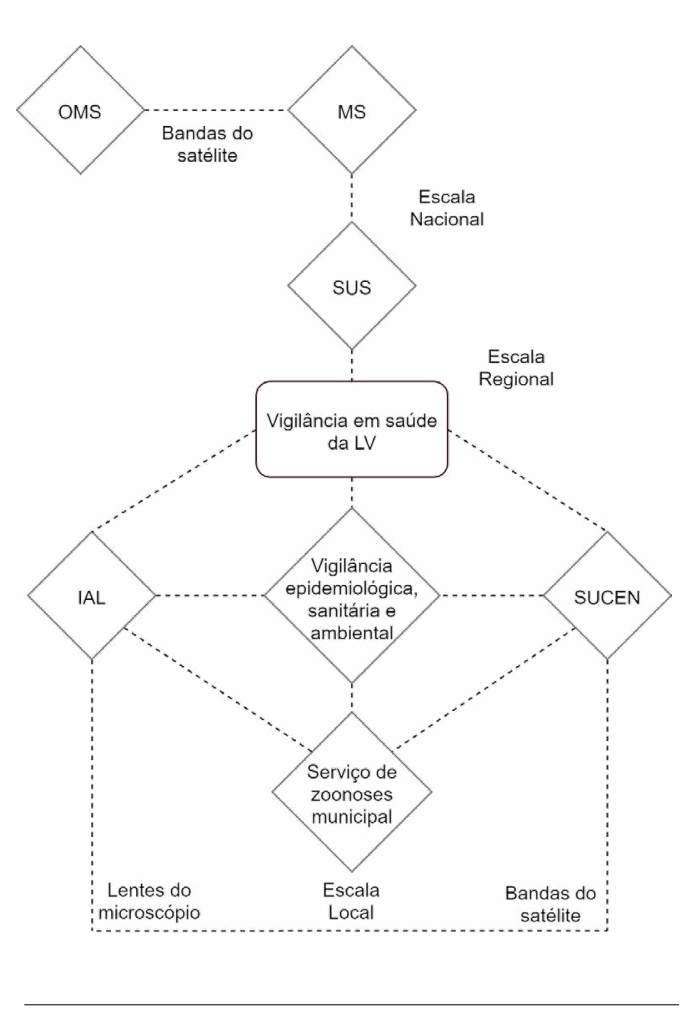

Figura 3. Esquema da atuação relacional de diferentes órgãos dos sistemas de saúde responsáveis pela vigilância da leishmaniose visceral: escala de atuação e escala do fenômeno.

Observa-se, deste modo, que as diferentes escalas que compõem as decisões sobre a doença não conseguem pensar a LV por meio da escala geográfica, tornando a política susceptível e frágil diante das dificuldades encontradas no cenário da LV. Por isso, há a necessidade de o fenômeno ser entendido a partir de diferentes escalas sobrepostas: da local à global, do microscópio ao satélite. Deve haver uma interação entre as diferentes escalas que ajudam a promover saúde.

\section{Transposição de escalas: acontecer solidário}

Vimos que a saúde pública trabalha com as regiões sem considerar que, ao recortar um certo fenômeno, sua delimitação não respeita as fronteiras. Isso pode ser exemplificado através da ocorrência de casos de LV, em que o ciclo da doença possui um parasito, vetor e hospedeiro, em um dado ambiente, e que não estão restritos a uma escala específica. 


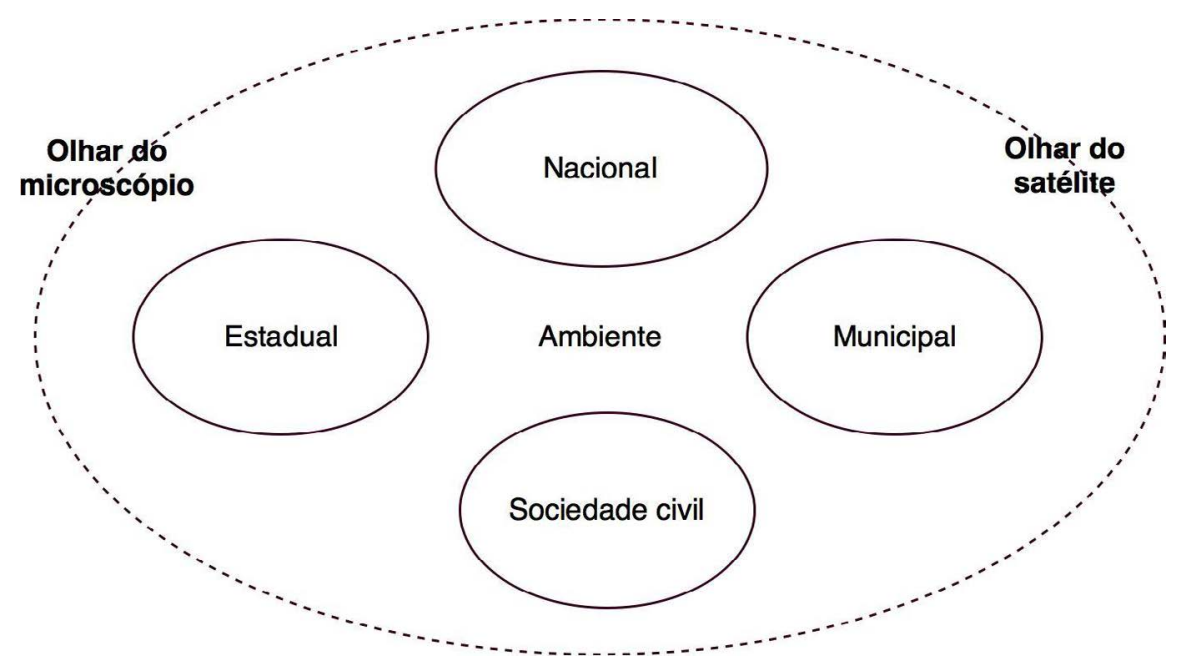

Figura 4. Componentes da leishmaniose visceral em escalas.

Nesse sentido, as doenças são exemplos da necessidade de se transpor as escalas. Não basta que existam órgãos que lidem com os componentes da doença por si só, trabalhando o caso canino, o caso humano, o vetor, o ambiente ou o parasito. É preciso mais. Faz-se necessário que todas as escalas que compõem a vigilância e o controle da doença trabalhem em conjunto, de forma integrada, juntamente com a sociedade civil, no intercambiar de informações em diferentes níveis de escala, num acontecer solidário ${ }^{26}, \mathrm{o}$ que nos levaria ao uso totalis da noção de escala geográfica, já que esta é produzida pelas relações sociais dos atores políticos em jogo ${ }^{4}$.

Mais do que estabelecer uma hierarquia de escalas, conforme nos lembra Smith ${ }^{4}$, é preciso saltar escalas, por meio da conexão social e política que oferece um princípio unitário para as abstrações geográficas que o conceito de escala constrói. É necessário que se faça uma transposição de escalas (Figura 5), em que os diferentes níveis de atuação (políticos ou da sociedade civil) sejam instrumentalizados juntamente com os parceiros do SUS, para a co-gestão dos serviços, potencializando suas múltiplas articulações ${ }^{11}$. Não entendemos a transposição simplesmente como representar o fenômeno em diferentes escalas, mas ir além, mesclar, dissolver, cortar, intersectar diferentes níveis de escala. $\mathrm{O}$ espaço construído pela escala geográfica deve ser pensado numa visão de contexto. Temos que ser criativos e trazer outras formas que não apenas a materialidade expressa nestes espaços no ambiente vivido.

Nesse contexto, a região se impõe como um espaço de manifestação da solidariedade entre os parceiros que compartilham a gestão do sistema ${ }^{11}$. Devemos construir as regiões de saúde a partir da concepção dialética da totalidade, pensando não na soma das partes, mas no todo, na decomposição do todo para entender a coisa ${ }^{27}$, que traz em si a escala geográfica.

A reflexão de se pensar as regiões de saúde traria a noção de totalidade, nos aproximando de uma leitura geográfica. Trata-se de apreender o real em sua totalidade, onde o gestor/planejador de saúde possa propor uma visão totalizante do mundo, pensando em um mundo globalizado. $\mathrm{O}$ planeta, entendido como entidade material e humana, e cada um dos seus momentos, a história, constituem-se totalidades em permanente processo de totalização. A totalidade é uma categoria analítica capaz de ajudar a construir uma teoria e uma epistemologia do espaço geográfico ${ }^{26}$, em consonância com as categorias geográficas e o conceito de escala geográfica.

Ao dialogar em diferentes escalas, estaríamos nos apropriando das escalas geográficas, pensando o espaço a partir das influências e políticas, fatos que explicam os problemas do fenômeno. Estaríamos, assim, nos aproximando da totalidade.

Para entender essa totalidade, convém inserir uma categoria elementar na discussão: o lu- 




Figura 5. Transposição dos componentes da leishmaniose visceral em escalas geográficas.

gar. Entender o ambiente vivido, as demandas de saúde e doença, que dialogando e transpondo diferentes escalas, produziria a escala geográfica.

Todavia, o lugar aparece adjacente a outras escalas que, impreterivelmente, no período técnico, científico e informacional em que vivemos, mundo e lugar se constituem num par indissociável, tornando, no entanto, o lugar a categoria real, concreta; é o espaço da existência e da coexistência ${ }^{28}$.

A distinção entre lugar e região passa quase que imperceptível e ambos definem-se como funcionalização do mundo e é por eles que o mundo é percebido empiricamente ${ }^{26}$. Ora estamos em uma escala, ora em outra; por isso a necessidade de transposição quando se trabalha com uma concepção geométrica do espaço geográfico.

A região pode ser considerada como um lugar e os lugares podem ser regiões e nada mais são do que uma abstração se o considerarmos sem a totalidade. Devemos respeitar a autonomia dos municípios e, ao mesmo tempo, romper os limites jurídico-administrativos, desagregando a informação no nível que cabe ao fenômeno social. Dessa forma, cabe-nos desenvolver uma metodologia que nos permita trabalhar as regiões então pensadas de diferentes naturezas, resultando no entendimento do conteúdo dinâmico das redefinições regionais ${ }^{11}$. Trata-se, portanto, de pensar o diálogo, o intercâmbio, o salto e a transposição de escalas. O que não é tarefa simples.

\section{Considerações}

O conceito de escala geográfica nos incita a pensar na necessidade de uma reflexão teóricometodológica no campo das políticas de ação. Embora a política não trabalhe com a reflexão dos conceitos, usa-os. Falta-lhes uma discussão epistemológica e ontológica do conceito de escala, fugindo das acepções meramente hierárquicas e geométricas. Defendemos que o conceito não deve ser somente usado, mas refletido também neste campo.

Trazer o debate teórico-metodológico dos conceitos geográficos para as políticas de planejamento seria pensar uma proposta escalar em cooperação, em que se perpassaria os limites do recorte, se romperia com os limites territoriais, não respeitando somente os limiares dos municípios, mas do fenômeno estudado, já que sua materialização ocorre de uma forma em âmbito da política pública, e de outra no espaço.

A região de saúde, espaço político-operativo do sistema de saúde, é passível de acontecimentos e deve ser entendida como um espaço em construção e reconstrução permanente. Por via institucional, é possível maior sinergia entre os diferentes órgãos gestores dos serviços de saúde, juntamente com a sociedade civil ${ }^{11}$, na transposição de escalas, saltando-as, intercambiando informações e produzindo saúde num acontecer solidário ${ }^{26}$.

É preciso que se perceba o processo de diferenciação espacial em relação com os processos sociais mais amplos, que sejam redesenhadas as regiões e as escalas que condizam com o fenômeno em diferentes momentos e que estas últimas sejam articuladas.

A escala geográfica para a saúde, deveria ser, sine qua non, a fusão dos conceitos de escala, região, paisagem, território e lugar, em um acontecer solidário no tempo. Tudo isso impresso no espaço, a síntese desses conceitos. 


\section{Colaboradores}

PSS Matsumoto escreveu o rascunho inicial, apontando as principais ideias a partir do olhar da universidade. LAZ D'Andrea contribuiu com sua visão de universidade e como gestora de saúde, auxiliando na redação final do texto.

\section{Agradecimentos}

Agradecemos especialmente ao Prof. Dr. Marcio José Catelan, que provocou o debate sobre as escalas em nossas pesquisas, contribuindo para delinear as ideias aqui escritas. Agradecemos a Fundação de Amparo à Pesquisa do Estado de São Paulo (FAPESP) que financiou a pesquisa.

\section{Referências}

1. Bahiana LCC. Contribuição ao estudo da Questão da escala na Geografia: escalas em geografia urbana. Rio de Janeiro: Universidade Federal do Rio de Janeiro; 1952.

2. Castro IE. O problema da escala. In: Castro IE, Gomes PC, Corrêa RL, organizadores. Geografia: Conceitos e Temas. $3^{\mathrm{a}}$ ed. Rio de Janeiro: Betrand Brasil; 2011. p. 521-538.

3. Racine J, Raffestin C, Ruffy V. Escala e ação, contribuições para uma interpretação do mecanismo de escala na prática da geografia. Revista brasileira de Geografia 1983; 1:123-36.

4. Smith N. Contornos de uma política espacializada: veículos dos sem-teto e produção de escala geográfica. In: Arantes A, organizador. O espaço da diferença Campinas: Papirus; 2000. p. 131-175.

5. Melazzo ES, Castro AC. A escala geográfica: noção, conceito ou teoria? Terra Livre 2007; 2(29):133-142.

6. Souza ML. Escala geográfica, "construção social da escala” e "políticas de escala." In: Souza ML. Os conceitos fundamentais da pesquisa sócio-espacial. Rio de Janeiro: Bertrand Brasil; 2013. p. 179-216.

7. Nunes ED. A construção teórica na sociologia da saúde: uma reflexão sobre a sua trajetória. Cien Saude Colet 2014; 19(4):1007-1018.

8. Nunes ED. A sociologia da saúde no Brasil - a construção de uma identidade. Cien Saude Colet 2014; 19(4):1041-1052.

9. Langdon EJ. Os diálogos da antropologia com a saúde: contribuições para as políticas públicas. Cien Saude Colet 2014; 19(4):1019-1029.

10. Barros NF. O ensino das ciências sociais em saúde: entre o aplicado e o teórico. Cien Saude Colet 2014; 19(4):1053-1063.

11. Guimarães RB. Regiões de saúde e escalas geográficas. Cad Saude Publica 2005; 21(4):1017-1025.

12. Tian N, Goovaerts P, Zhan FB, Wilson JG. Identification of racial disparities in breast cancer mortality: does scale matter? Int J Health Geogr 2010; 9:35.

13. Chen Z, Gotway Crawford CA. The role of geographic scale in testing the income inequality hypothesis as an explanation of health disparities. Soc Sci Med 2012; 75(6):1022-1031.

14. Reardon SF, Farrell CR, Matthews SA, O'Sullivan D, Bischoff K, Firebaugh G. Race and space in the 1990s: Changes in the geographic scale of racial residential segregation, 1990-2000. Soc Sci Res 2009; 38(1):55-70

15. Parenteau M-P, Sawada MC. The modifiable areal unit problem (MAUP) in the relationship between exposure to NO2 and respiratory health. Int J Health Geogr 2011; 10:58.

16. Gracie R, Barcellos C, Magalhães M, Souza-Santos R, Barrocas PRG. Geographical scale effects on the analysis of leptospirosis determinants. Int J Environ Res Public Health 2014; 11(10):10366-10383.

17. Reardon SF, Matthews SA, O'Sullivan D, Lee BA, Firebaugh G, Farrell CR, Bischoff A. The Geographic Scale of Metropolitan Racial Segregation. Demography 2008; 45(3):489-514.

18. Brasil. Decreto $n^{\circ} 7.508$, de 28 de junho de 2011. Regulamenta a Lei no 8.080 , de 19 de setembro de 1990 , para dispor sobre a organização do Sistema Único de Saúde - SUS, o planejamento da saúde, a assistência à saúde e a articulação interfederativa, e dá outras providências. Diário Oficial da União 2011; 29 jun. 
19. Brasil. Portaria $N^{\circ} 373$, de 27 de fevereiro de 2002. Diário Oficial da União 2002; 28 Fev.

20. Brasil. Ministério da Saúde (MS). Manual de Vigilância e Controle da Leishmaniose Visceral. MS; 2014. [acessado 2017 Mar 17]. Disponível em: http://bvsms. saude.gov.br/bvs/publicacoes/manual_vigilancia_ controle_leishmaniose_visceral_ledicao.pdf.

21. Center for Disease Control and Prevention (CDC). 2016. [acessado 2017 Mar 17]. Disponível em: https:// www.cdc.gov/parasites/leishmaniasis/prevent.html.

22. World Helth Organization (WHO). Neglected diseases. 2016. [acessado 2017 Mar 17]. Disponível em: http:// www.who.int/neglected_diseases/en/.

23. World Helth Organization (WHO). Control of the Leishmaniases. WHO Expert Comm Control Leishmaniases, Geneva, 22-26 March 2010. 2010; March:22-6. [acessado 2017 Mar 17]. Disponível em: http://apps.who.int/iris/bitstream/10665/44412/1/ WHO_TRS_949_eng.pdf.

24. World Helth Organization (WHO). Informe Epidemiológico das Américas - Escritório Regional para as Américas. Brasília: WHO; 2015.

25. Brasil. Ministério da Agricultura (MA). Nota Técnica No 11/2016 - MAPA. Cpv/Dfip/Sda/Gm/Mapa - MA 2016. [acessado 2017 Mar 17]. Disponível em: http:// www.agricultura.gov.br/

26. Santos M. A natureza do espaço. $4^{\text {a }}$ ed. São Paulo: Edusp; 2008.

27. Karel K. Dialética do concreto. $2^{\text {a }}$ ed. Rio de Janeiro: Paz e Terra; 1976.

28. Santos M. O retorno do território. OSAL: Observatorio Social de América Latina 2005; 6(16):251-261.

Artigo apresentado em 30/04/2017

Aprovado em 24/03/2018

Versão final apresentada em 26/03/2018 